\title{
Methods for a Seamless Transition From Tracheostomy to Spontaneous Breathing in Patients With COVID-19
}

\author{
Miguel J Divo, Catherine L Oberg, Michael A Pritchett, Bartolome R Celli, and Erik E Folch
}

\author{
Introduction \\ Methodology \\ Tracheostomy in Severe COVID-19 \\ Rationale for the Procedure \\ Timing \\ Location \\ Percutaneous Versus Open \\ Initial Tracheostomy Tube Choice \\ Placement of the Gastrostomy Tube \\ Rationale for Placement \\ Timing \\ Location \\ Technique \\ Caring for the COVID-19 Patient With Tracheostomy \\ Identification of Aerosol-Generating Procedures \\ Liberation From Mechanical Ventilation \\ Secretion Clearance \\ Diagnostic Maneuvers \\ Therapeutic Procedures \\ Inhaled Therapeutics \\ Preparing for the Unexpected \\ Accidental Displacement of the Tracheostomy Tube \\ Accidental PEG Tube Removal \\ Summary
}

The COVID-19 pandemic has profoundly affected health care delivery worldwide. A small yet significant number of patients with respiratory failure will require prolonged mechanical ventilation while recovering from the viral-induced injury. The majority of reports thus far have focused on the epidemiology, clinical factors, and acute care of these patients, with less attention given to the recovery phase and care of those patients requiring extended time on mechanical ventilation. In this paper, we review the procedures and methods to safely care for patients with COVID-19 who require tracheostomy, gastrostomy, weaning from mechanical ventilation, and final decannulation. The guiding principles consist of modifications in the methods of airway care to safely prevent iatrogenesis and to promote safety in patients severely affected by COVID-19, including mitigation of aerosol generation to minimize risk for health care workers. Key words: tracheostomy tube; COVID-19; aerosol-generating procedures; personal protective equipment; percutaneous endoscopic gastrostomy tube. [Respir Care 2020;65(11):1773-1783. (C) 2020 Daedalus Enterprises] 


\section{Tracheostomy Care in Patients With COVID-19}

\section{Introduction}

The current coronavirus disease 2019 (COVID-19) pandemic has disrupted the world's health care systems. While the majority of reports have focused on the epidemiology, clinical course, and acute care of these patients, less attention has been given to their management during recovery from the acute injury. ${ }^{1-3} \mathrm{~A}$ recent report highlighted the importance of post-acute care facilities and noted an urgent need to adjust the capability of these facilities to serve as effective "pop-off valves" to assist survivors of severe COVID-19. ${ }^{4}$

It is estimated that up to $5 \%$ of patients infected by the virus require mechanical ventilation. The natural course of these patients is still not well established, although data from several studies suggest a relatively prolonged duration of mechanical ventilation. A review of patients from Wuhan, China indicated that, of 37 subjects with ARDS, 20 were alive at day 28 and required some form of ventilatory support. ${ }^{5}$ In a series of 21 critically ill subjects with COVID-19 in Washington state, $71 \%$ required mechanical ventilation. At day $25,38 \%$ continued to require this therapy. ${ }^{3}$ Finally, most patients requiring mechanical ventilation have multiple comorbidities and are frail, likely requiring prolonged recovery time. These data highlight the prolonged nature of respiratory failure in critically ill patients with COVID-19 and the need for a longer-term care plan transition.

Mechanical ventilation has greatly impacted the overall mortality of critically ill patients with respiratory failure

\footnotetext{
Drs Divo and Celli are affiliated with the Pulmonary and Critical Care Division, Brigham and Women's Hospital, Boston, Massachusetts. Drs Divo and Celli are affiliated with the Spaulding Rehabilitation Hospital, Cambridge, Massachusetts. Dr Oberg is affiliated with the Division of Pulmonary, Critical Care Medicine, Clinical Immunology, and Allergy, UCLA Medical School, Los Angeles, California. Dr Pritchett is affiliated with FirstHealth of the Carolinas, Pinehurst, North Carolina. Dr Folch is affiliated with the Division of Pulmonary and Critical Care Medicine, Massachusetts General Hospital, Boston, Massachusetts.
}

Dr Pritchett has disclosed relationships with Medtronic, BodyVision, Intuitive Surgical, Philips, Biodesix, AstraZeneca, Johnson \& Johnson, United Therapeutics, Actelion, Inivata, Pfizer, Ambu, and Boston Scientific. Dr Folch has disclosed relationships with Medtronic, Cook Medical, Boston Scientific, and Intuitive Surgical. The other authors have disclosed no conflicts of interest.

Supplementary material related to this paper is available at http://www. rcjournal.com.

Correspondence: Miguel J Divo MD MPH, Brigham and Women's Hospital, Pulmonary and Critical Care Division, 75 Francis St, Boston, MA 02115.E-mail:mdivo@bwh.harvard.edu.

DOI: $10.4187 /$ respcare. 08157 due to COVID-19 infection. However, there are new challenges posed by the increasing numbers of survivors of the acute phase who now require prolonged care. For example, the timing and technique to perform tracheostomies in these patients are not clear. Even less is known about the practical modifications needed to safely care for patients with a tracheostomy tube as they continue the journey toward liberation from mechanical ventilation, while simultaneously minimizing the risk of exposure to health care personnel. Historically, the care is often fragmented because the physicians performing the tracheostomy are typically not the same as those faced with the process of weaning from mechanical ventilation and ultimate decannulation or with the rehabilitation process leading to full recovery. The COVID-19 pandemic presents a unique challenge to health care personnel because the virus is highly contagious. These professionals work in close proximity to patients for prolonged periods of time, perform high-risk aerosol-generating procedures, and may have suboptimal personal protective equipment (PPE) ${ }^{6-}$ ${ }^{8}$ Currently, there is no targeted treatment for COVID-19, therefore efforts must be focused on prevention while we await outcomes of the trials currently under study as well as the development of an effective vaccine. How long patients remain contagious after clinical recovery remains uncertain, thus testing guidelines may need to be revised as additional information becomes available.

In response to these uncertainties, we convened a working group of experts with experience across the continuum of care, from ICUs to long-term care facilities, with 3 goals in mind. First, we aim to provide guidance on tracheostomy and gastrostomy tubes and their long-term management in patients with COVID-19 who survive mechanical ventilation. Second, we seek to provide recommendations and modifications of standard practices to minimize exposure to aerosols, which can then be implemented in care bundles for tracheostomy teams. Third, this work is intended to serve as a resource to achieve a seamless transition from the ICU stay to recovery in patients afflicted by COVID-19 who require prolonged mechanical ventilation.

\section{Methodology}

The working group, was formed by experts with experience in the areas of tracheostomy and percutaneous endoscopic gastrostomy (PEG) tube placement as well as the management of long-term mechanical ventilation/tracheostomy and weaning. Two of the authors are interventional pulmonologists, one is an advanced bronchoscopist, and the remaining 2 authors are pulmonologists with extensive experience $\mathrm{n}$ long-term ventilatory management, weaning, and tracheostomy weaning/decannulation. The group performed a review of the available literature from the COVID-19 pandemic as well as prior pandemics using the following strategy. First, we searched for published society 
Tracheostomy Care in Patients With COVID-19

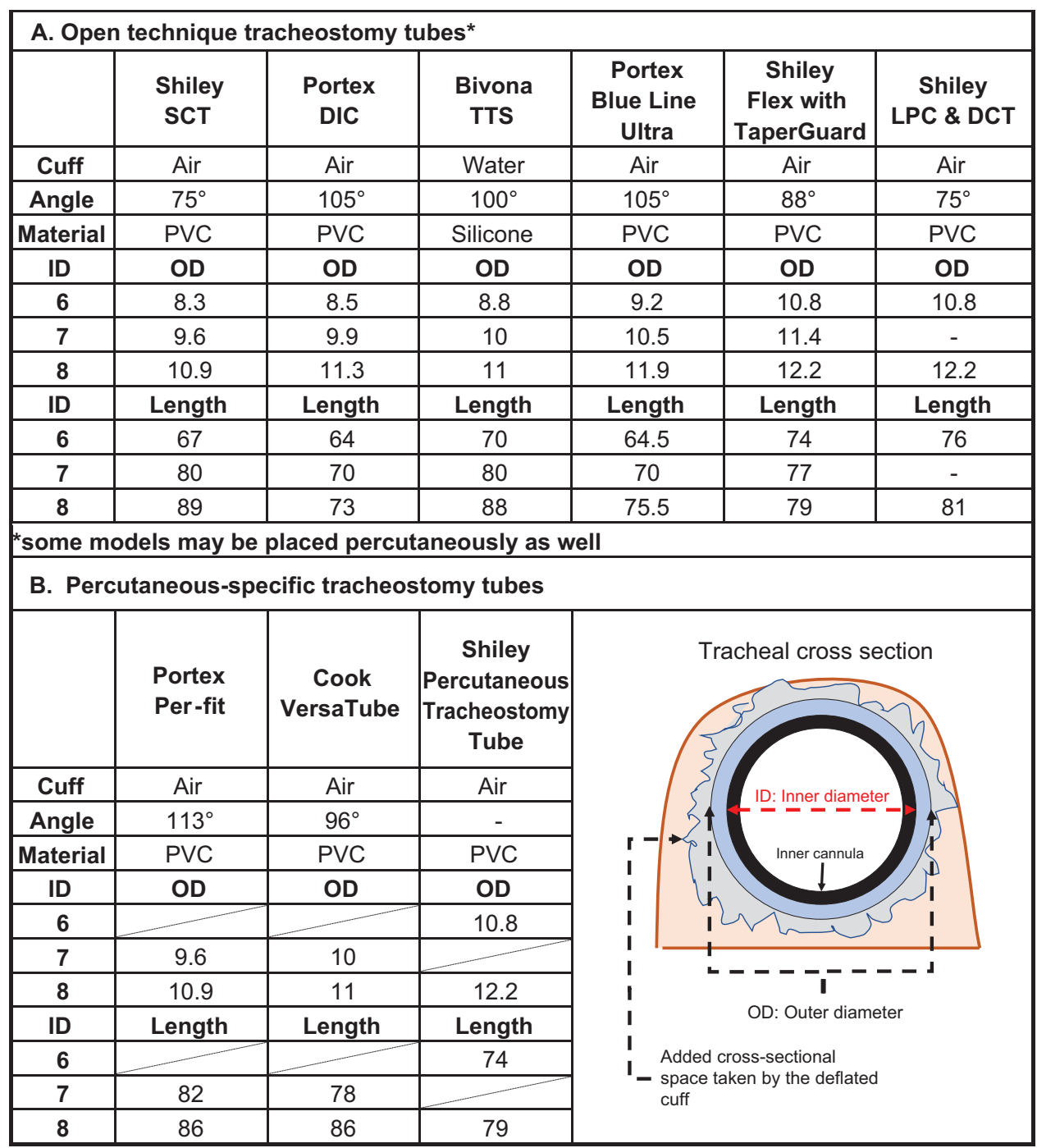

Fig. 1. Comparison of commonly used tracheostomy tubes. SCT $=$ single cannula tracheostomy, DIC $=$ disposable inner cannula, $T$ TS $=$ tight to shaft, $\mathrm{LPC}=$ low pressure cuff, $\mathrm{DCT}=$ disposable cannula tracheostomy, $\mathrm{PVC}=$ polyvinyl chloride, ID $=$ inner diameter, $\mathrm{OD}=$ outer diameter.

guidelines addressing tracheostomy tube and PEG tube placement and management of prolonged mechanical ventilation in patients with COVID-19. Specifically, we searched the following sites: Centers for Disease Control and Prevention (CDC), American Association for Respiratory Care, American Thoracic Society, American College of Chest Physicians, American Academy of Otolaryngology-Head and Neck Surgery, Society of Thoracic Surgeons, European Respiratory Society, and Society for Advanced Bronchoscopy. We also searched web pages for any published guidelines on the topic as of April 20, 2020. Second, we searched MEDLINE (PubMed) and Google Scholar for primary literature addressing the key points of this review: viral transmission, aerosol-generating procedures, tracheostomy and PEG placement (ie, technique, timing), PPE for airborne pathogens, and epidemiologic reports addressing super-spreading events. In
Figure 1, we extracted product specifications from manufacturers of tracheostomy tubes. From these searches, a total of 107 articles were extracted and discussed by all authors in an iterative process. The final recommendations are the results of distilling the information obtained from the above process and the group's firsthand experience.

\section{Tracheostomy in Severe COVID-19}

\section{Rationale for the Procedure}

Placement of a tracheostomy tube in patients with prolonged respiratory failure has shown advantages such as reduced work of breathing, improved secretion management, patient comfort, enhanced communication, and reduced need for sedation and paralytics, ${ }^{9,10}$ with the latter 2 aspects linked to serious long-term weakness and delirium. ${ }^{11}$ Tracheostomies 


\section{Tracheostomy Care in Patients With COVID-19}
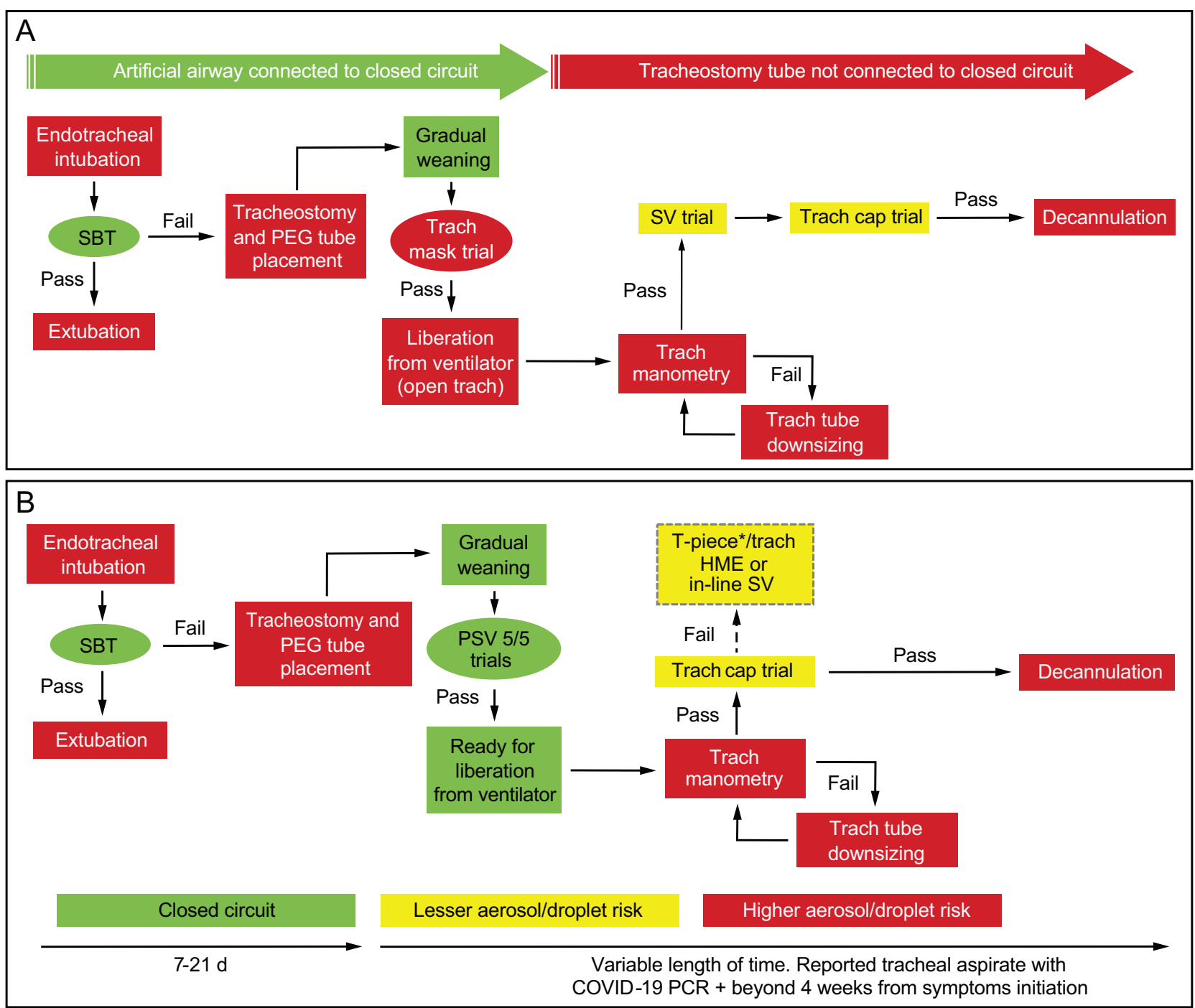

Fig. 2. Comparison of management strategies in patients with prolonged mechanical ventilation in the COVID-19 era. A: Standard management of prolonged respiratory failure and ventilator weaning. B: Suggested modifications for patients with COVID-19. SBT =spontaneous breathing trial, PEG = percutaneous endoscopic gastrostomy, SV = speaking valve, PSV = pressure-support ventilation, HME = heat-and-moisture exchanger, $\mathrm{PCR}=$ polymerase chain reaction.

also help facilitate the shift away from intensive care areas to areas of hospitals or rehabilitation facilities that specialize in the long-term management of these patients. For patients failing spontaneous breathing trials or extubation efforts, well-timed tracheostomies decrease the use of scarce resources such as intravenous sedatives, neuromuscular blockers, and ICU beds. This is particularly important during the COVID-19 pandemic as many health care systems have been overwhelmed by these patients and have been forced to transform multiple care areas into distinct COVID-19 units, often cannibalizing the functional capacity of other important areas of the hospitals.

Advanced planning is paramount because post-tracheostomy care also requires detailed protocols to minimize aerosol-generating procedures and to maximize the safety of health care personnel. In the COVID-19 era, initial decisions may have secondary effects that may place other downstream health care workers at increased risk unnecessarily (Fig. 2A). The care of these patients therefore should be a joint effort between pre- and post-tracheostomy practitioners. The creation of a multidisciplinary tracheostomy team and the use of care bundles has been shown to decrease the time to decannulation and to improve patient satisfaction (a practical example of a bundle is provided in the supplementary materials at http://www.rcjournal.com). ${ }^{12-14}$

\section{Timing}

In the current COVID-19 pandemic, there is limited high-quality data to guide us on the optimal timing of 


\section{Tracheostomy Care in Patients With COVID-19}

tracheostomy. In reaction to this pandemic, most society guidelines recommended either avoiding tracheostomy placement due to the risks to health care personnel, or waiting at least 2-3 weeks after intubation and preferably until COVID-19 testing is negative. ${ }^{15}$

While agreeing with the concern for risks to health care personnel, we feel that these opinion-based guidelines are overly conservative. They do not consider the risks of prolonged intubation and resource utilization from delaying tracheostomy placement. Furthermore, these guidelines do not reflect the limited value of a negative nasopharyngeal COVID-19 swab as viral replication and shedding may persist in the distal airways and parenchyma. ${ }^{16,17}$

A recent publication from New York described the authors' experience with a modified technique used in 98 patients. ${ }^{18}$ Their average timing for tracheostomy was $10.6 \pm 5 \mathrm{~d}$ of mechanical ventilation prior to tracheostomy placement. Importantly, none of the health care providers developed symptoms or tested positive for COVID-19. ${ }^{18}$ Based on this experience, as well as similar statements from other expert groups, ${ }^{19,20}$ we recommend proceeding with tracheostomy after $10 \mathrm{~d}$ of mechanical ventilation in those patients where spontaneous awakening trials and spontaneous breathing trials have failed. It is important to avoid extubation of patients who have a high likelihood of re-intubation and, instead, to proceed with tracheostomy without undue delays. The high ventilator settings seen in patients with COVID-19 and ARDS are not a contraindication to proceed with tracheostomy, although subcutaneous emphysema may be encountered..$^{21-23}$

\section{Location}

We recommend placing tracheostomy tubes at bedside in the ICU rather than in the operating room. This method confers multiple advantages, including a controlled environment with nursing and respiratory therapy who have expertise in critical care. This location also offers the benefits of minimized use of PPE, minimized transport (and therefore less contamination of other areas), and a reduced number of health care personnel involved in these highly aerosolizing procedures. The use of negative-pressure rooms (including operating rooms) is strongly recommended but should be tailored to local availability and in coordination with infection control staff..$^{24,25}$

\section{Percutaneous Versus Open}

The choice between surgical or percutaneous dilatational tracheostomy is largely determined by each institution's resources and expertise, as tracheostomies can be performed by surgeons and more often by non-surgeons. ${ }^{26}$ Society guidelines may reflect a specific technique based on their general practice preference. ${ }^{27}$ However, in patients with COVID-19 who require a tracheostomy, the procedure should be performed by the most experienced operator, in the safest manner, using the shortest possible procedure duration, and preferably at the bedside to limit cross-contamination during transport. Based on these factors, we recommend the percutaneous technique, which has been shown to provide these benefits. ${ }^{28-30}$

Percutaneous Tracheostomy. We recommend the use of bronchoscopy to minimize misplacement, bleeding from vessels located in the paratracheal area, and injury to the posterior wall of the trachea. However, if using bronchoscopy, one must selectively withhold mechanical ventilation and proceed expeditiously during the aerosolizing parts of the procedure. We recommend minimizing the number of personnel in the room and encourage the use of neuromuscular blockade. The experience of the 2 operators involved should ensure that the bronchoscopy portion as well as the percutaneous tracheal access and introduction of the tracheostomy tube are done in rapid sequence. A novel technique recently described involves passing the bronchoscope alongside the endotracheal tube rather than through it. ${ }^{18}$ This technique limits the visualization of the posterior wall at the time of the procedure and requires pulling back the endotracheal tube with a deflated cuff when the tracheostomy tube is inserted. It also requires withholding mechanical ventilation during specific steps; it is, however, an interesting alternative to the traditional bronchoscopeguided technique and was used with great success at the pioneering institution. A more detailed review of the standard technique is described in detail elsewhere. ${ }^{31}$

Open/Surgical Tracheostomy. In patients with COVID-19, special consideration should be given to the inherent need for transport to the operating room, with the resulting increase in delays, health care personnel exposure during transportation, and PPE use. Additional recommendations from the Society for Advanced Bronchoscopy advocate minimizing tracheal suctioning, withholding mechanical ventilation prior to incision of the trachea while deflating the cuff of the endotracheal tube to avoid accidental puncture, and using petroleum gauze around the site to minimize air leak. ${ }^{32}$ A more detailed description of the open/surgical tracheostomy technique is available elsewhere. ${ }^{33}$

\section{Initial Tracheostomy Tube Choice}

The type of tracheostomy tube chosen for initial placement has a significant impact on future weaning and decannulation decisions. This is particularly important in patients with COVID-19 because these procedures are aerosol-generating. Appropriate choices of size and model can minimize the need for future downsizing while providing an effective artificial airway. Characteristics such as inner 


\section{Tracheostomy Care in Patients With COVID-19}
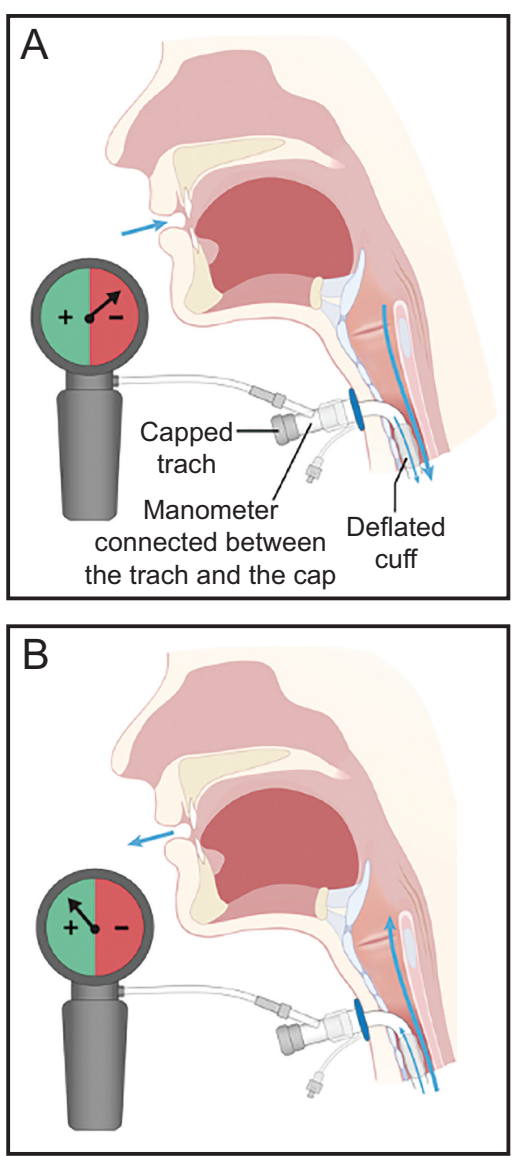

Fig. 3. To prepare a patient for manometry, the tracheostomy tube cuff is deflated and secretions are suctioned. An adapter is attached to the tracheostomy tube. The side port is connected via oxygen tubing to a pressure manometer that has been zeroed, and a speaking valve or cap (or finger occlusion with a gloved finger) is attached to the end of the adapter. The averaged inspiratory $(A)$ and expiratory (B) pressures (negative and positive, respectively) from at least 5 quiet breaths not during phonation or cough are recorded. Lowflow resistance is suggested when expiratory pressures are $0-5 \mathrm{~cm}$ $\mathrm{H}_{2} \mathrm{O}$. For capping, it is also important to measure the inspiratory pressures. Values between 0 and $-3 \mathrm{~cm} \mathrm{H}_{2} \mathrm{O}$ suggest low inspiratory resistance, and capping is deemed safe; values $>5 \mathrm{~cm} \mathrm{H}_{2} \mathrm{O}$ for expiration and $<-3 \mathrm{~cm} \mathrm{H}_{2} \mathrm{O}$ require careful consideration for either tube downsizing or airway inspection. Regardless of measurements, always observe the patient for overt signs and symptoms of difficulty breathing. More detailed information is available in Reference 49.

diameter, outer diameter, angle, length, and presence of an inner cannula should all be taken into consideration (Fig. 1). The outer diameter differs between tracheostomy models with the same inner diameter. The outer diameter plays a role during speaking and capping trials because it determines to what degree the trachea is blocked by the tube and ultimately may impact the need for downsizing (Fig. 3). ${ }^{34}$ We suggest that the operator's primary consideration should be choosing the most effective inner diameter while minimizing the outer diameter. Tubes with an inner diameter of 7-8 mm will fit most adults while providing both less airway resistance and the ability to perform bronchoscopy if needed. Tracheal size (sagittal and coronal dimensions) is smaller in females compared to males and correlates with the patient's height. ${ }^{35-38}$ We suggest choosing a tracheostomy tube with an inner diameter of $7 \mathrm{~mm}$ for females with a height of $150-180 \mathrm{~cm}$ and for males with a height $<160$ $\mathrm{cm}$. In males $>160 \mathrm{~cm}$ tall and females $>180 \mathrm{~cm}$ tall, we recommend a tube with an inner diameter of $8 \mathrm{~mm}$. Specialized tracheostomy tubes (ie, extra-long tubes, flexible tubes, and adjustable flange tubes) should be reserved for cases where the tracheal anatomy warrants it (eg, patient body habitus and neck circumference). A good general rule is that if the punch-dilator needs to be hubbed to the skin to be visible during the percutaneous tracheostomy, the patient is likely to benefit from a longer tracheostomy tube or an angle that allows it to clear the existing excess soft tissue.

Finally, a tube with a disposable inner cannula will reduce the inner diameter by $1 \mathrm{~mm}$ and will result in increased resistance, but a disposable inner cannula may be helpful because it can be easily replaced if the tube becomes occluded. ${ }^{39}$

\section{Placement of the Gastrostomy Tube}

\section{Rationale for Placement}

We recognize that placement of a PEG tube may not be routine or available in all centers performing tracheostomies. Compared to a nasogastric tube, a PEG tube provides more secure access to the gastrointestinal tract. Nasogastric tubes are frequently dislodged and, when they are replaced, they require radiographic confirmation of placement. This is particularly important in a patient with COVID-19 because both the replacement and the radiograph will expose more providers to viral particles. Additionally, nasogastric tubes can cause occlusive sinusitis and pressure ulcers in the nostrils and nasal septum, particularly in patients who have a lengthy recovery process. Nasogastric tubes also interfere with swallowing and can be more uncomfortable compared to a PEG tube. One key observation we have seen in these patients is the profound neuromuscular weakness and weight loss that occur; therefore, ensuring uninterrupted nutrition is key. Because retraining the swallowing function and regaining the strength and coordination to use feeding utensils can take weeks, a PEG tube remains the safest approach to transition to spontaneous feeding trials. Our recommendation of combining tracheostomy and PEG placement into a single procedure is of particular importance during the COVID-19 pandemic because it minimizes health care personnel exposure on multiple levels. 


\section{Tracheostomy Care in Patients With COVID-19}

\section{Timing}

For patients with COVID-19, we suggest combining the placement of percutaneous and PEG tube in a single episode performed by a highly efficient team with expertise in both procedures. This joint placement minimizes the risk of aerosol generation seen when these proecdures are performed at separate times and has the advantage of a single anesthetic event. The practice patterns for placement of gastrostomy tubes for ongoing enteral nutrition versus continued nasogastric or orogastric temporary tubes are highly variable. The surgical placement of a gastrostomy tube could be considered in patients who are going to the operating room for another indication.

\section{Location}

During the COVID-19 pandemic, limiting patient transfers to other areas of the hospital is important, therefore we recommend placement at the bedside, ideally coupled with tracheostomy placement to limit exposure to health care personnel. These procedures are considered aerosol-generating procedures and should ideally take place in a negative-pressure room.

\section{Technique}

Ultimately, the goal with patients with COVID-19 is to decrease exposure risk of health care personnel while providing efficient, effective, and safe medical care. We therefore recommend endoscopic placement at the bedside. Gastrostomy tubes can be placed endoscopically, surgically, or by interventional radiology, with the choice depending on local expertise, and less commonly on anatomic considerations. ${ }^{40,41}$ Regardless of which technique is chosen, it should be performed by an experienced operator. Appropriate PPE, which includes an N-95 mask, face shield, gown, and gloves, should be worn throughout the procedure.

\section{Caring for the COVID-19 Patient With Tracheostomy}

\section{Identification of Aerosol-Generating Procedures}

Caring for mechanically ventilated patients carries a risk of droplet or aerosol generation that may contaminate exposed individuals. As shown in Figure 2A, the risk depends on the degree to which the system is open to the environment. When the patient is in a closed system (shown in green), the caregiver and surroundings are less likely to be contaminated. The risk increases as the system becomes more open, such as when transitioning a patient to a trach mask or performing a speaking valve trial (shown in red). Routine steps that are often performed during the prolonged care of these patients, such as secretion clearance, suctioning for diagnostic samples, bronchoscopies, and the administration of inhaled medications, also carry a higher risk. The general guiding principles are:

- Avoid unnecessary treatments: reconsider which maneuvers or procedures are essential and avoid routine or automatic practices such as use of bronchodilators, routine tracheostomy tube changes, or downsizing of the tracheostomy before assessing tolerance of capping.

- Favor procedures based on closed-circuit techniques. When there are no alternatives, bundle high-risk tracheostomy care procedures (eg, suctioning, tracheal manometry, capping) to an individual care team, in a single setting.

- Within a closed-circuit setup, use viral filters. Review manufacturer-recommended filters, time for replacement, and approved accessories to deliver inhaled therapeutics.

- Practitioners should abide by airborne precautions and wear proper PPE as recommended by the CDC (https:// www.cdc.gov/coronavirus/2019-ncov/hcp/infectioncontrol.html, Accessed September 16, 2020).

\section{Liberation From Mechanical Ventilation}

Liberation from mechanical ventilation is an important milestone in a patient's recovery from prolonged respiratory failure. In Figure 2A, we provide a general outline for the process of liberating patients from mechanical ventilation and their progress to decannulation. It is based on proven strategies that include assessment for readiness for spontaneous breathing trials, ${ }^{42}$ a respiratory therapistdriven weaning protocol, ${ }^{43}$ and an integrated tracheostomy decannulation protocol. In Figure 2B and Figure 4, section A, we highlight the suggested alternatives to key aerosolgenerating steps to minimize health care personnel's exposure risk to SARS-CoV-2.

While on mechanical ventilation, the risk of exposure to others is relatively low because the circuit is closed and few particles, if any, escape to the surrounding environment unless there is an air leak. The same is true if the patient has a capped tracheostomy tube because the risk is similar to that of nontracheostomized patients. If the patient is breathing with an oxygen or humidified mask while the tracheostomy tube is open, or if they have been decannulated and the stoma is open, the risk for droplet or aerosol generation is high. ${ }^{44-46}$ The risk while using a speaking valve with a humidified mask is unclear. 


\section{Tracheostomy Care in Patients With COVID-19}

\begin{tabular}{|c|c|c|c|}
\hline Current Practice & Suggested Modification & \multicolumn{2}{|c|}{ Notes/Comments } \\
\hline \multicolumn{4}{|l|}{ A. Weaning Process } \\
\hline Mechanical ventilation & None & \multirow{2}{*}{\multicolumn{2}{|c|}{$\begin{array}{l}\text { By design done in a closed circuit, } \\
\text { however, always monitor for air leaks }\end{array}$}} \\
\hline Pressure support wean & None & & \\
\hline SBT via trach mask & $\begin{array}{l}\text { SBT with pressure } \\
\text { support } 0 / 0,0 / 5 \text { or } 5 / 5 \\
\text { to allow tube resistance } \\
\text { compensation }\end{array}$ & \multicolumn{2}{|c|}{$\begin{array}{l}\text { Allows for in-line suction and } \\
\text { therapeutics in closed circuit }\end{array}$} \\
\hline $\begin{array}{l}\text { One-way speaking valve } \\
\text { (SV) }\end{array}$ & $\begin{array}{l}\text { If possible, skip 1-way } \\
\text { SV and go directly to } \\
\text { tracheostomy cap } \\
\text { If needed use in-line SV }\end{array}$ & $\begin{array}{l}\text { Scan the QR code } \\
\text { to see demo of in- } \\
\text { line SV }\end{array}$ & 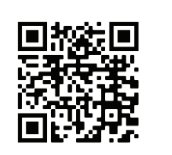 \\
\hline Trach cap & None & \multicolumn{2}{|c|}{$\begin{array}{l}\text { Dressing over tracheostoma to avoid } \\
\text { leaks. Patient to use face mask during } \\
\text { interactions. }\end{array}$} \\
\hline
\end{tabular}

B. Secretion Clearance \begin{tabular}{l||l}
\hline $\begin{array}{l}\text { Tracheal suction (not } \\
\text { mechanically ventilated) }\end{array}$ & $\begin{array}{l}\text { T-piece with in-line suction and filter (see the supplementary } \\
\text { materials at http://www.rcjournal.com) }\end{array}$
\end{tabular}

\begin{tabular}{|c|c|c|c|}
\hline $\begin{array}{l}\text { Mechanical } \\
\text { insufflation-exsufflation } \\
\text { via trach (MI-E) }\end{array}$ & $\begin{array}{l}\text { Indicated for patient } \\
\text { with neuromuscular } \\
\text { weakness } \\
\text { Poor cough effort } \\
(\text { PEF }<160 \mathrm{~L} / \mathrm{min})^{45}\end{array}$ & \multicolumn{2}{|c|}{$\begin{array}{l}\text { Use a viral filter in the circuit } \\
\text { Operator to wear enhanced airborne } \\
\text { PPE } \\
\text { Avoid face mask MI-E }\end{array}$} \\
\hline $\begin{array}{l}\text { Flutter valves: Acapella, } \\
\text { Aerobika }\end{array}$ & \multicolumn{3}{|c|}{$\begin{array}{l}\text { Designed to loosen mucus and induce cough therefore is } \\
\text { considered higher risk. }\end{array}$} \\
\hline Incentive spirometry & Probably okay & \multicolumn{2}{|c|}{ Use if suspect atelectasis } \\
\hline \multicolumn{4}{|l|}{ C. Procedures } \\
\hline \multicolumn{3}{|c|}{$\begin{array}{l}\text { General precautions for all procedures: } \\
\text { - For all procedures use airborne precautions as guided by the CDC } \\
\text { - In addition, consider the use of additional physical barrier to contain droplets } \\
\text { (eg, clear plastic sheet or acrylic box) }\end{array}$} & 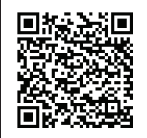 \\
\hline $\begin{array}{l}\text { Tracheostomy tube } \\
\text { downsize }\end{array}$ & \multicolumn{3}{|c|}{$\begin{array}{l}\text { - Need for downsizing guided by tracheostomy manometry (see } \\
\text { text and Figure 2) } \\
\text { - Avoid "routine" trach change } \\
\text { - Always downsize to lower OD (see Table 1) } \\
\text { - Consider a TTS cuff or cuffless model }\end{array}$} \\
\hline Bronchoscopy & \multicolumn{2}{|c|}{$\begin{array}{l}\text { Consider the use of a swivel adaptor instead of } \\
\text { bronchoscope over open trach }\end{array}$} & \\
\hline Decannulation & \multicolumn{3}{|c|}{ Follow general precautions above } \\
\hline
\end{tabular}

\section{Diagnostics}

\begin{tabular}{|l||l|l|}
\hline End tidal $\mathbf{C O}_{2}$ & Use ABG-VBG & Must use proper PPE \\
\hline \multirow{2}{*}{ Transtracheal manometry } & None & $\begin{array}{l}\text { Follow general precautions for all } \\
\text { procedures as described above }\end{array}$ \\
\hline Mechanics & \multicolumn{2}{|c|}{ Performed in-line using ventilator's diagnostics and graphs } \\
\hline
\end{tabular}

Fig. 4. Suggested modifications to usual practice to reduce aerosol and droplet generation. SBT $=$ spontaneous breathing trial, $\mathrm{PEF}=$ peak expirtory flow, PPE = personal protective equipment, $\mathrm{OD}=$ outer diamter, $\mathrm{TTS}=$ tight to shaft, $\mathrm{ABG}-\mathrm{VBG}=$ arterial blood gas-venous blood gas. 


\section{Tracheostomy Care in Patients With COVID-19}

Given the potential risks outlined, we suggest the following modifications:

- When a patient reaches the spontaneous breathing trial stage, it is best to consider CPAP with enough support to compensate for the tube and circuit resistance ( $0 / 0$ to $5 / 5 \mathrm{~cm} \mathrm{H}_{2} \mathrm{O}$ pressure) instead of the open tracheostomy mask. This will allow suctioning and administration of inhaled therapies while decreasing the opening of the ventilator circuit, thereby reducing the potential for exposure without delaying liberation from mechanical ventilation.

- When considering a valve to facilitate speech, we recommend using an in-line valve connected to the ventilator circuit.

- If tolerated, we recommend bypassing the speaking valve trial and proceeding directly to tracheostomy capping trials.

- If there is a need to liberate the patient from the ventilator or the patient cannot be decannulated, a T-piece with in-line suction, viral filter, and condensation collector is a feasible alternative (see the supplementary materials at http://www.rcjournal.com).

\section{Secretion Clearance}

The airway clearance procedures frequently performed in patients with prolonged respiratory failure are summarized in Figure 4, section B. Of these procedures, incentive spirometry is relatively safe but should only be used in patients where there is an indication, such as the presence of atelectasis. The same applies to mechanical insufflation-exsufflation devices, which should only be considered for specific patients with ineffective cough. ${ }^{47}$ The use of devices that require respiratory effort, which results in expulsion of particles into the environment, such as flutter valves and oscillating positive expiratory pressure devices, should be avoided. For tracheal suctioning, we recommend performing in-line suctioning through a T-piece with a filter (see the supplementary materials at http://www.rcjournal.com).

\section{Diagnostic Maneuvers}

Assessing pulmonary mechanics to evaluate a patient's respiratory reserve is usually done via a closed system and thus is relatively safe. This is not the case when measuring exhaled end-tidal $\mathrm{CO}_{2}$ levels or performing tracheostomy tube manometry. In place of end-tidal $\mathrm{CO}_{2}$ monitoring, we recommend using either venous or arterial blood gases to evaluate $\mathrm{CO}_{2}$ levels or transcutaneous capnography, if available. $^{48}$

Tracheostomy tube manometry (Fig. 3) can be a valuable tool to estimate a patient's readiness for use of a speaking valve or ability to tolerate capping. This maneuver measures the intratracheal airway pressures during inspiration and expiration as a surrogate for air-flow resistance around the tracheostomy tube while the patient is spontaneously breathing. Expiratory pressures $>5 \mathrm{~cm} \mathrm{H}_{2} \mathrm{O}$ and inspiratory pressures with values $<-3 \mathrm{~cm} \mathrm{H}_{2} \mathrm{O}$ suggest obstruction of air flow and indicate the need for tracheostomy tube downsizing or airway inspection. ${ }^{49}$ Although performing tracheal manometry requires a deflated cuff, it is quite informative regarding the need for tracheostomy downsizing. It is, however, an aerosol-generating procedure and warrants the use of appropriate PPE in the patient with COVID-19.

\section{Therapeutic Procedures}

If a tube change is needed, the clinician should consider the current phase of the weaning process; if the patient requires mechanical ventilation, then a cuffed tube is indicated, and we suggest replacing the tube with either a tightto-shaft model of the same size or a traditional cuffed model that is $1-2$ sizes smaller. If the patient has been liberated from mechanical ventilation, we recommend assessing the need for a cuffed tracheostomy tube. The benefit of the tight-to-shaft or cuffless tube is that it does not create additional tracheal occlusion from the deflated cuff. See the illustration in Figure 1 and a suggested checklist for tracheostomy tube change in the supplementary materials (available at http://www.rcjournal.com).

Bronchoscopy is sometimes needed in patients with chronic respiratory failure; however, it is considered a highrisk aerosol-generating procedure. Refer to issued guidelines for more specific information and indications for bronchoscopy amid the COVID-19 pandemic. Additionally, these documents provide recommendations on best practices, should bronchoscopy be performed (Fig. 4, section C). ${ }^{32}$

\section{Inhaled Therapeutics}

In general, scheduled bronchodilators should be avoided unless the patient has a clear clinical indication. These therapies are not mandatory in all ventilated patients. Consider a long-acting or ultra-long-acting medication to minimize the number of potential exposures to those administering such medications. In patients who are mechanically ventilated, in-circuit nebulized or pressurized metered-dose inhaler medications should be used preferentially, including long-acting medications. In tracheostomized patients, long-acting medication delivered via a pressurized metered-dose inhaler with a spacer can be adapted to fit the tracheostomy tube. In patients who are decannulated, either a dry powder or slow-mist inhaler is preferred (see the supplementary materials at http://www. rcjournal.com for a decision algorithm and a list of 


\section{Tracheostomy Care in Patients With COVID-19}

inhaled medications, administration routes, and dosage frequencies).

\section{Preparing for the Unexpected}

For accidental dislodgement of tracheostomy or PEG tubes, we strongly recommend having readily deployable PPE and barriers because these are high-risk aerosol- and droplet-generating situations.

\section{Accidental Displacement of the Tracheostomy Tube}

Accidental partial displacement or total decannulation of the tracheostomy tube occurs in up to $1.5 \%$ of tracheostomized patients and can result in significant hypoxia and death. We recommend following the suggested algorithm to manage accidental decannulation (see the supplementary materials at http://www.rcjournal.com). ${ }^{22,50}$ All situations (eg, oral intubation, bronchoscopic-guided or direct tracheostomy tube replacement, or close clinical monitoring with the tracheostomy removed) should be considered aerosolgenerating procedures in the patient with COVID-19.

\section{Accidental PEG Tube Removal}

Inadvertent removal of a PEG tube may also occur, particularly in patients who are combative or in an altered mental state. Similar to accidental decannulation, the management of accidental gastrostomy tube removal depends on how long the tube has been in place and whether there is a well-formed fistula track. Strategies are described in detail elsewhere..$^{51,52}$ In both early and late accidental dislodgement, rapid action should be taken to avoid closure of the stoma.

\section{Summary}

The COVID-19 pandemic has impacted the delivery of care worldwide. A significant fraction of patients affected by SARS-CoV-2 will require prolonged mechanical ventilation and percutaneous enteral nutrition. Careful coordination through the continuum of care to minimize aerosolization of viral particles is likely to have a beneficial impact on the safety of health care providers while minimizing the waste of PPE. The use of tracheostomy and gastrostomy tubes facilitates the transition of care from acute to sub-acute facilities, thereby decreasing the burden on inpatient hospital systems; it also allows the weaning process to begin. The methods and algorithms described here should make the transition of mechanically ventilated patients with COVID-19 from the intensive care they required to the long-term care they need not only more seamless, but also safer for everyone.

\section{ACKNOWLEDGMENTS}

The authors thank Julie Silva RRT, Joseph Maloof RRT, Elizabeth Kamau RRT, Thomas Briana RRT, Marie St. Hubert RRT, and Jennifer Winget RRT from the Respiratory Care Department at Spaulding Rehabilitation Hospital-Cambridge, and Dr Katherine Haley from the Brigham and Women's Hospital for their valuable suggestions. We also thank Ms Sue Lee for the graphic design of figures.

\section{REFERENCES}

1. Zhou F, Yu T, Du R, Fan G, Liu Y, Liu Z, et al. Clinical course and risk factors for mortality of adult inpatients with COVID-19 in Wuhan, China: a retrospective cohort study. Lancet 2020;395 (10229):1054-1062.

2. Ruan Q, Yang K, Wang W, Jiang L, Song J. Clinical predictors of mortality due to COVID-19 based on an analysis of data of 150 patients from Wuhan, China. Intensive Care Med 2020;368(2):846848 .

3. Arentz M, Yim E, Klaff L, Lokhandwala S, Riedo FX, Chong M, et al. Characteristics and outcomes of 21 critically ill patients with COVID19 in Washington state. JAMA 2020;323(16): 1612.

4. Grabowski DC, Joynt Maddox KE. Postacute care preparedness for COVID-19: thinking ahead. JAMA 2020;323(20):2007-2008.

5. Yang X, Yu Y, Xu J, Shu H, Xia J, Liu H, et al. Clinical course and outcomes of critically ill patients with SARS-CoV-2 pneumonia in Wuhan, China: a single-centered, retrospective, observational study. Lancet Respir Med 2020;8(5):475-481.

6. Chow EJ, Schwartz NG, Tobolowsky FA, Zacks RLT, HuntingtonFrazier M, Reddy SC, et al. Symptom screening at illness onset of health care personnel with SARS-CoV-2 infection in King County, Washington. JAMA 2020;323(20):2087-2089.

7. Heinzerling A, Stuckey PMJ, Scheuer T, Xu K, Perkins KM, Resseger $\mathrm{H}$, et al. Transmission of COVID-19 to health care personnel during exposures to a hospitalized patient - Solano County, California. MMWR Morb Mortal Wkly Rep 2020;69(15):472-476.

8. CDC COVID-19 Response Team. Characteristics of health care personnel with COVID-19 - United States, February 12 - April 9, 2020. MMWR Morb Mortal Wkly Rep 2020;69(15):477-481.

9. Diehl JL, El Atrous S, Touchard D, Lemaire F, Brochard L. Changes in the work of breathing induced by tracheotomy in ventilator-dependent patients. Am J Respir Crit Care Med 1999;159(2):383-388.

10. Epstein SK. Late complications of tracheostomy. Respir Care 2005;50 (4):542-549.

11. Shehabi Y, Bellomo R, Reade MC, Bailey M, Bass F, Howe B, et al. Early intensive care sedation predicts long-term mortality in ventilated critically ill patients. Am J Respir Crit Care Med 2012;186(8):724731.

12. Divo MJ. Post-tracheostomy care: bundle up for success! Respir Care 2017;62(2):246-247.

13. Mah JW, Staff II, Fisher SR, Butler KL. Improving decannulation and swallowing function: a comprehensive, multidisciplinary approach to post-tracheostomy care. Respir Care 2017;62(2):137-143.

14. Rak KJ, Ashcraft LE, Kuza CC, Fleck JC, DePaoli LC, Angus DC, et al. Effective care practices in patients receiving prolonged mechanical ventilation: an ethnographic study. Am J Respir Crit Care Med 2020;201(7):823-831.

15. Chao TN, Braslow BM, Martin ND, Chalian AA, Atkins JH, Haas AR, et al. Tracheotomy in ventilated patients with COVID-19. Ann Surg 2020;272(1):e30-e32.

16. Chen C, Gao G, Xu Y, Pu L, Wang Q, Wang L, et al. SARS-CoV-2positive sputum and feces after conversion of pharyngeal samples in patients with COVID-19. Ann Intern Med 2020;172(12):832-834. 


\section{Tracheostomy Care in Patients With COVID-19}

17. Wang W, Xu Y, Gao R, Lu R, Han K, Wu G, Tan W. Detection of SARS-CoV-2 in different types of clinical specimens. JAMA 2020;323(18):1843-1844.

18. Angel L, Kon ZN, Chang SH, Rafeq S, Shekar SP, Mitzman B, et al. Novel percutaneous tracheostomy for critically ill patients with COVID-19. Ann Thorac Surg 2020;110(3):1006-1019.

19. Lamb CR, Desai NR, Angel L, Chaddha U, Sachdeva A, Sethi S, et al. Use of Tracheostomy During the COVID-19 Pandemic:American College of Chest Physicians/American Association for Bronchology and Interventional Pulmonology/Association of Interventional Pulmonology Program Directors Expert Panel Report. Chest 2020 [Epub ahead of print]

20. McGrath BA, Brenner MJ, Warrillow SJ, Pandian V, Arora A, Cameron TS, et al. Tracheostomy in the COVID-19 era: global and multidisciplinary guidance. Lancet Respir Med 2020;8(7):717-725.

21. Beiderlinden M, Groeben H, Peters J. Safety of percutaneous dilational tracheostomy in patients ventilated with high positive end-expiratory pressure (PEEP). Intensive Care Med 2003;29(6):944-948.

22. Fernandez-Bussy S, Mahajan B, Folch E, Caviedes I, Guerrero J, Majid A. Tracheostomy tube placement: early and late complications. J Bronchology Interv Pulmonol 2015;22(4):357-364.

23. Rashid AO, Islam S. Percutaneous tracheostomy: a comprehensive review. J Thorac Dis 2017;9(Suppl 10):S1128-S1138.

24. Tay JK, Khoo ML-C, Loh WS. Surgical considerations for tracheostomy during the COVID-19 pandemic: lessons learned from the severe acute respiratory syndrome outbreak. JAMA Otolaryngol Head Neck Surg 2020;146(6):517-518.

25. Wei WI, Tuen HH, Ng RWM, Lam LK. Safe tracheostomy for patients with severe acute respiratory syndrome. Laryngoscope 2003;113(10):1777-1779.

26. Goldenberg D, Ari EG, Golz A, Danino J, Netzer A, Joachims HZ. Tracheotomy complications: a retrospective study of 1130 cases. Otolaryngol Head Neck Surg 2000;123(4):495-500.

27. Iftikhar IH, Teng S, Schimmel M, Duran C, Sardi A, Islam S. A network comparative meta-analysis of percutaneous dilatational tracheostomies using anatomic landmarks, bronchoscopic, and ultrasound guidance versus open surgical tracheostomy. Lung 2019;197(3):267-275.

28. Brass P, Hellmich M, Ladra A, Ladra J, Wrzosek A. Percutaneous techniques versus surgical techniques for tracheostomy. Cochrane Database Syst Rev 2016;7(7):CD008045.

29. Klotz R, Klaiber U, Grummich K, Probst P, Diener MK, Büchler MW, Knebel P. Percutaneous versus surgical strategy for tracheostomy: protocol for a systematic review and meta-analysis of perioperative and postoperative complications. Syst Rev 2015;4(1):1-5.

30. Kost KM. Endoscopic percutaneous dilatational tracheotomy: a prospective evaluation of 500 consecutive cases. Laryngoscope 2005;115 (S107):1-30

31. Madi JM, Trottier SJ. Percutaneous dilatational tracheostomy technique. J Bronchol Interv Pulmonol 2003;10(2):146-148.

32. Pritchett MA, Oberg CL, Belanger A, De Cardenas J, Cheng G, Nacheli GC, et al. Society for Advanced Bronchoscopy consensus statement and guidelines for bronchoscopy and airway management amid the COVID-19 pandemic. J Thorac Dis 2020;12(5):1781-1798.

33. Muscat K, Bille A, Simo R. A guide to open surgical tracheostomy. Shanghai Chest 2017;1:4-4.
34. Hess DR, Altobelli NP. Tracheostomy tubes. Respir Care 2014;59 (6):956-971.

35. Breatnach E, Abbott GC, Fraser RG. Dimensions of the normal human trachea. AJR Am J Roentgenol 1984;142(5):903-906.

36. Coordes A, Rademacher G, Knopke S, Todt I, Ernst A, Estel B, Seidl RO. Selection and placement of oral ventilation tubes based on tracheal morphometry. Laryngoscope 2011;121(6):1225-1230.

37. Stern EJ, Graham CM, Webb WR, Gamsu G. Normal trachea during forced expiration: dynamic CT measurements. Radiology 1993;187 (1):27-31.

38. Sanchez I, Pasterkamp H. Tracheal sound spectra depend on body height. Am Rev Respir Dis 1993;148(4 Pt 1):1083-1087.

39. Pryor LN, Baldwin CE, Ward EC, Cornwell PL, O'Connor SN, Chapman MJ, Bersten AD. Tracheostomy tube type and inner cannula selection impact pressure and resistance to air flow. Respir Care 2016;61(5):607-614.

40. Folch E, Kheir F, Mahajan A, Alape D, Ibrahim O, Shostak E, Majid A. Bronchoscope-guided percutaneous endoscopic gastrostomy tube placement by interventional pulmonologists: a feasibility and safety study. J Intensive Care Med 2020;35(9):851-857.

41. Given MF, Hanson JJ, Lee MJ. Interventional radiology techniques for provision of enteral feeding. Cardiovasc Intervent Radiol 2005;28 (6):692-703.

42. Jubran A, Grant BJB, Duffner LA, Collins EG, Lanuza DM, Hoffman LA, Tobin MJ. Effect of pressure support vs unassisted breathing through a tracheostomy collar on weaning duration in patients requiring prolonged mechanical ventilation: a randomized trial. JAMA 2013;309(7):671-677.

43. Scheinhorn DJ, Chao DC, Stearn-Hassenpflug M, Wallace WA. Outcomes in post-ICU mechanical ventilation: a therapist-implemented weaning protocol. Chest 2001;119(1):236-242.

44. Anfinrud P, Stadnytskyi V, Bax CE, Bax A. Visualizing speech-generated oral fluid droplets with laser light scattering. N Engl J Med 2020;382(21):2061-2063.

45. Bourouiba L. Images in clinical medicine: a sneeze. N Engl J Med 2016;375(8):e15.

46. Tran K, Cimon K, Severn M, Pessoa-Silva CL, Conly J. Aerosol generating procedures and risk of transmission of acute respiratory infections to healthcare workers: a systematic review. PloS One 2012;7(4): e35797.

47. Bach JR, Saporito LR. Criteria for extubation and tracheostomy tube removal for patients with ventilatory failure: a different approach to weaning. Chest 1996;110(6):1566-1571.

48. Restrepo RD, Hirst KR, Wittnebel L, Wettstein R. AARC clinical practice guideline: transcutaneous monitoring of carbon dioxide and oxygen. Respir Care 2012;57(11):1955-1962.

49. Johnson DC, Campbell SL, Rabkin JD. Tracheostomy tube manometry: evaluation of speaking valves, capping and need for downsizing. Clin Respir J 2009;3(1):8-14.

50. O'Connor HH, White AC. Tracheostomy decannulation. Respir Care 2010;55(8):1076-1081.

51. Marshall JB, Bodnarchuk G, Barthel JS. Early accidental dislodgement of PEG tubes. J Clin Gastroenterol 1994;18(3):210-212.

52. Prosser B. Common issues in PEG tubes-what every fellow should know. Gastrointest Endosc 2006;64(6):970-972. 